\title{
Subclavian and axillary arterial aneurysms: two case reports
}

\author{
Aneurismas do segmento subclávio-axilar: relato de dois casos \\ Fernando Pinho Esteves', André Ventura Ferreira', Vanessa Prado dos Santos², \\ Gabriel Santos Novaes', Álvaro Razuk Filho', Roberto Augusto Caffaro'
}

\begin{abstract}
Aneurysms of the subclavian-axillary segment are rare, but when diagnosed they must be treated. This article describes two cases of aneurysms of the upper extremities, one in a subclavian artery and the other in an axillary artery. The first case was a 71-year-old male with a pulsating supraclavicular bulge on the right and muscle weakness in the ipsilateral extremity. Duplex scanning and arteriography confirmed the diagnosis of aneurysm of the right subclavian artery and the patient underwent aneurysmectomy and end-to-end anastomosis. The second case was a 24-year-old female patient, with no history of comorbidities, who presented with a pulsating mass in the right axillary region and paresthesia of the ipsilateral extremity. Duplex scanning and arteriography confirmed an aneurysm in the right axillary artery, which was successfully treated with aneurysmectomy and end-to-end anastomosis. Pathology findings showed that the first case was an atherosclerotic aneurysm and the second was a congenital aneurysm.
\end{abstract}

Keywords: aneurysm; subclavian artery; axillary artery; surgery.

\begin{abstract}
Resumo
Os aneurismas do segmento subclávio-axilar são de ocorrência rara e, uma vez diagnosticados, devem ser tratados. Neste trabalho, relatamos dois casos de aneurismas de membros superiores, sendo um da artéria subclávia e outro da artéria axilar. No primeiro caso, o paciente de 71 anos, sexo masculino, apresentava abaulamento pulsátil supraclavicular direito associado à fraqueza muscular no membro ipsilateral. Foram realizados duplex scan e arteriografia, que confirmaram o diagnóstico de aneurisma da artéria subclávia direita, sendo o paciente submetido à aneurismectomia com anastomose término-terminal. No segundo caso, uma paciente de 24 anos, do sexo feminino, sem antecedentes mórbidos ou comorbidades, apresentava queixa de massa pulsátil na região axilar direita associada à parestesia no membro ipsilateral. O duplex scan e a arteriografia confirmaram o aneurisma da artéria axilar direita, que foi tratado com aneurismectomia e anastomose término-terminal com sucesso. O diagnóstico anátomo-clínico foi de aneurisma aterosclerótico no primeiro caso e, no segundo caso, de aneurisma congênito.
\end{abstract}

Palavras-chave: aneurisma; artéria subclávia; artéria axilar; cirurgia.

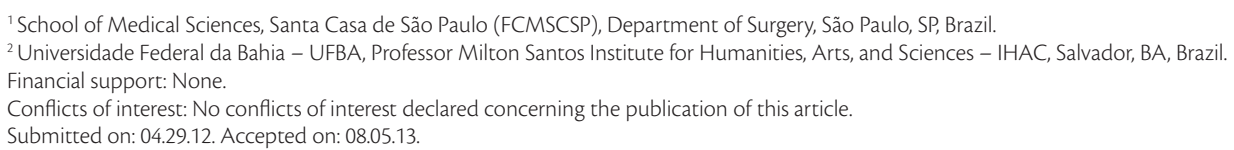




\section{INTRODUCTION}

Aneurysms can affect any of the arteries of the human body, but the subclavian-axillary segment is an uncommon site for this type of condition ${ }^{1}$. Hobson et al. conducted a literature review in 1982 and identified 195 cases of aneurysms in this topography, accounting for $1 \%$ of all peripheral aneurysms, $88 \%$ of which were in the subclavian artery $^{2}$.

In general, true aneurysms that involve the subclavian artery have atherosclerotic etiology. When these aneurysms emerge in the more distal segments of this artery or in the axillary artery, they may be associated with thoracic outlet syndrome ${ }^{1,3,4}$. Aneurysms in this territory can also be posttraumatic; infectious; associated with coarctation of the aorta; congenital; or related to Marfan syndrome and cystic necrosis of the tunica media ${ }^{1,5,6}$

When diagnosed, the literature recommends that aneurysms of the subclavian-axillary segment should be treated surgically, because of the risk of ischemic complications secondary to thromboembolic phenomena in upper extremities and in the carotid-vertebral territory, due to the possibility of retrograde embolization ${ }^{1,4,7}$. Furthermore, peripheral neurological symptoms such as chest pain, caused by compression of the brachial plexus, dysphagia and rupture are also possible elements in the clinical presentation, depending on the location and diameter of the aneurysm ${ }^{1,4}$.

In this article we describe two cases of aneurysms of the subclavian-axillary segment that were treated at our Vascular Service.

\section{CASE DESCRIPTIONS}

\section{Case 1}

The patient was a 71-year-old male with a history of difficult to control systemic arterial hypertension, myocardial revascularization (two saphenous vein grafts four years earlier) and a mitral valve replacement two years previously because of infectious endocarditis. He complained of a pulsating bulge in the right supraclavicular region with onset more than 1 year previously and episodes of muscle weakness in the upper homolateral extremity. There were no other complaints. Physical examination of the patient confirmed the presence of a pulsating mass in the right supraclavicular region and revealed normal pulses and perfusion in the ipsilateral extremity and no neurological deficits.

A duplex scan showed a fusiform aneurysm of the right subclavian artery. Arteriography was then conducted in order to plan surgery and once more the aneurysm was seen in the proximal third of the right subclavian artery, soon after the emergence of the right vertebral artery (Figure 1).

Conventional surgery was prescribed, approaching through a right-side supraclavicular incision, with ipsilateral sternoclavicular disarticulation and displacement of the clavicle downwards to expose the entire aneurysmal segment of the right subclavian artery. An aneurysm with diameter of $6 \mathrm{~cm}$ was observed (Figure 2). The artery was clamped proximally and distally and the aneurysm opened and it was possible to displace the artery sufficiently to conduct an end-to-end anastomosis (Figure 3) without the need for a graft. The patient complained of chest pains during the postoperative period, provoking an unconfirmed suspicion of acute myocardial infarction. Since the patient had a history of myocardial revascularization, his discharge was delayed after the procedure, despite good surgical results. The etiology of the aneurysm was diagnosed as atherosclerotic on the basis of pathology and clinical findings. The patient has been free from

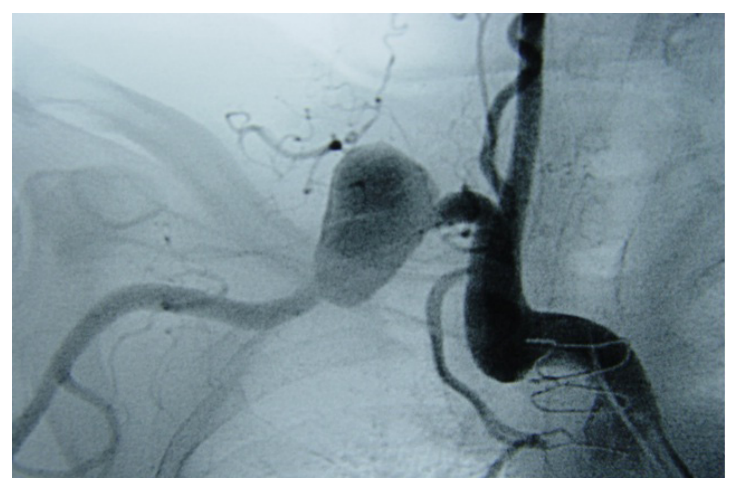

Figure 1. Arteriography of patient from case 1, showing extrathoracic aneurysm of the right subclavian artery.

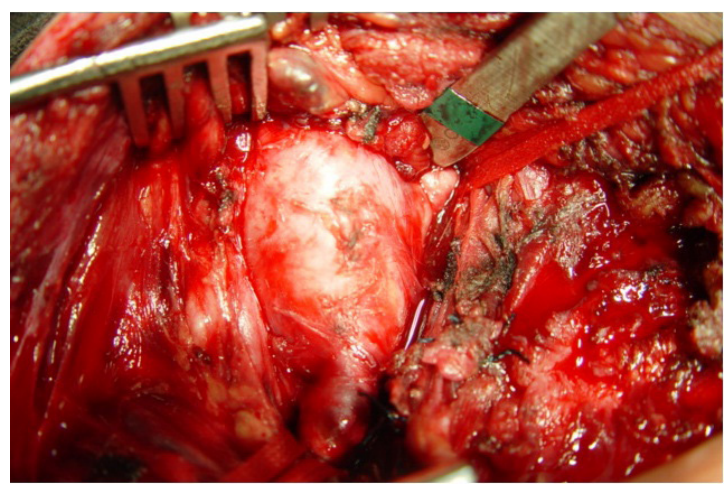

Figure 2. Intraoperative image of the right subclavian artery aneurysm, via right supraclavicular access. 


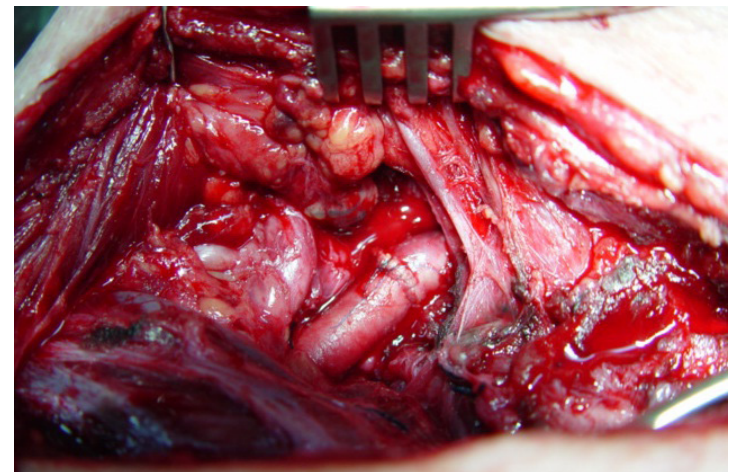

Figure 3. Final appearance of right subclavian artery with end-to-end anastomosis after resection of the aneurysmal dilatation.

postoperative complaints for 2 years of outpatients follow-up.

\section{Case 2}

A 24-year-old female patient with no history of traumatism or any comorbidities presented at our service with a pulsating mass in the right axillary region with onset two years previously. She complained of paresthesia in the right upper extremity, particularly if she held objects for more than 30 seconds and at night. Physical examination of the patient revealed a pulsating mass in the right axillary region, normal pulses and perfusion in the right upper limb and no neurological deficits.

A duplex scan showed a fusiform aneurysm of the right axillary artery. Digital subtraction angiography was conducted to plan surgery and it also confirmed the diagnosis (Figure 4). Conventional surgery was prescribed, with access via a right-side infraclavicular incision, and an aneurysmal dilatation with diameter of 4 $\mathrm{cm}$ was seen (Figure 5). The artery was clamped proximally and distally and the aneurysm sac was opened and found not to contain thrombi. Arterial reconstruction was achieved by dislocation of the proximal and distal portions of the artery and end-to-end anastomosis, with no need to use a graft (Figure 6). The patient was discharged from hospital on the third day after the operation, free from complaints. The final diagnosis, on the basis of pathology, was a congenital aneurysm. The patient was followed for one year and was free from complaints and all pulses were present and normal.

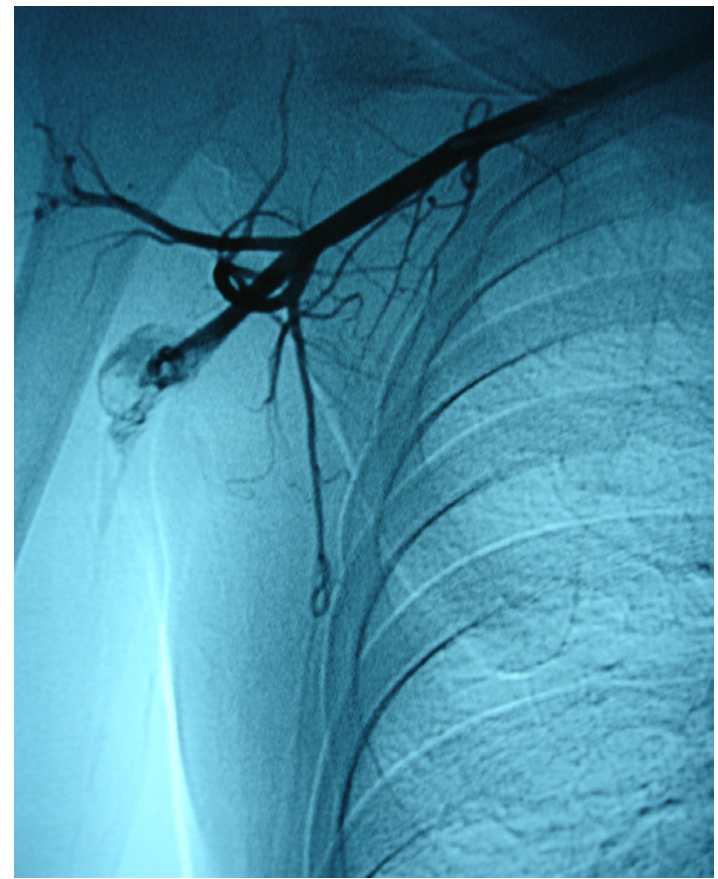

Figure 4. Arteriography of patient from case 2, showing right axillary artery aneurysm.

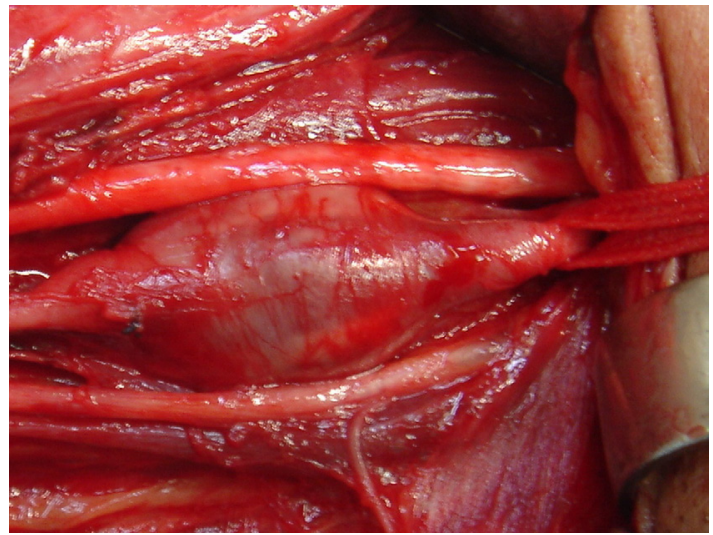

Figure 5. Intraoperative image of congenital aneurysm of the right axillary artery.

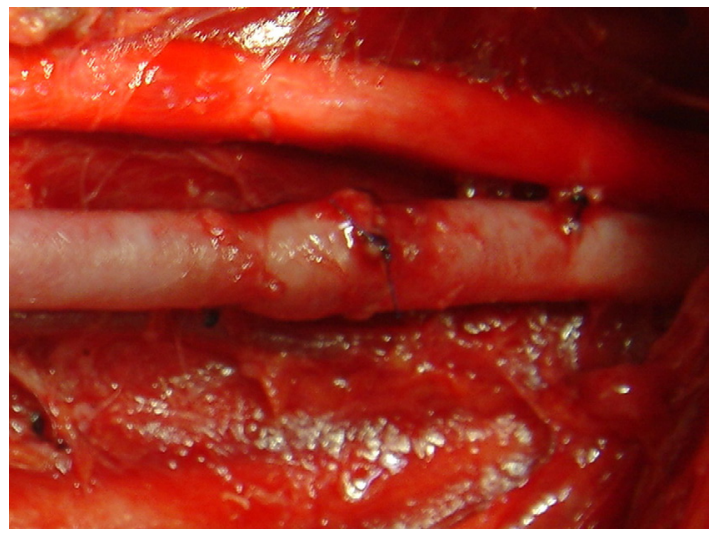

Figure 6. Final appearance of right axillary artery with end-toend anastomosis after resection of the aneurysmal dilatation. 


\section{DISCUSSION}

Aneurysms of the subclavian-axillary segment are rarer than other peripheral aneurysms, although their exact incidence is unknown ${ }^{1,8}$. They are generally subclassified as intrathoracic or extrathoracic, because both symptomology and the treatment approach chosen can differ between the two types ${ }^{1,4}$.

Patients may be asymptomatic, but they may also present a wide range of ischemic symptoms, signs secondary to compression of the brachial plexus and mediastinal symptoms ${ }^{1,4,9}$. The presence of a pulsating mass, with or without a palpable thrill, is one of the most often reported signs of extrathoracic aneurysms of the subclavian artery ${ }^{10,11}$. Both cases described here presented with a pulsating mass within the area of the aneurysm that was observed on physical examination and led to the diagnosis by ultrasonography.

In asymptomatic patients, a suspicion of aneurysm of the intrathoracic subclavian artery may be aroused by a chest X-ray, on which it will appear as a mediastinal mass, but they may be confused with tumors of the lung upper lobe $e^{5,12}$. Bin et al. ${ }^{13}$ and Takagi et al. ${ }^{14}$ have described cases of subclavian aneurysms in which patients suffered hoarseness, diplopia and hemoptysis. Other authors have described cases of respiratory insufficiency and upper digestive obstructions secondary to aneurysms of the subclavian artery ${ }^{15-17}$. These intrathoracic aneurysms may occur in subclavian arteries with aberrant origins ("Arteria Lusoria"), leading to symptoms of dysphagia ${ }^{1}$.

In the literature, the choice of diagnostic imaging methods for these cases depends both on the aneurysm site and on the evolution of image processing software over the years. Duplex scans are one method of initial diagnosis for extrathoracic aneurysms ${ }^{4,9}$. Since this is a rare disease, the majority of patient series and case reports describe angiography as playing a fundamental role in diagnosis, particularly when planning surgery for these patients, with emphasis when aneurysms are extrathoracic ${ }^{1,3,4,7,12}$. Computed tomography is also considered necessary for diagnostic examination, particularly for intrathoracic aneurysms ${ }^{4,18}$. Notwithstanding, a more recent case report used angiotomography for diagnosis and for planning surgery in a patient who underwent this imaging examination to investigate Marfan syndrome ${ }^{19}$. Thus, while the greater part of the literature recommends angiography for planning surgery, for investigating whether there are distal occlusive lesions, and for assessing the extent of the aneurysm and the patency of the contralateral vertebral artery, in cases in which the ipsilateral vertebral artery originates within the aneurysm, ${ }^{1,4}$ in practice it is being substituted by angiotomography. During the period in which the cases described here were treated, our service did not have angiotomography and so angiography was used to plan surgery after a duplex scan had diagnosed the aneurysm.

Surgical treatment is recommended for subclavianaxillary aneurysms in the literature, although the details of incidence rates of complications are unknown ${ }^{1,4}$. Surgical access to intrathoracic aneurysms of the subclavian artery depends on which side the aneurysm is. For aneurysms of the left subclavian artery, a left-side thoracotomy is used, whereas for aneurysms of the right subclavian, the need for better control of the ascending aorta and of the aneurysm's necks means that sternotomy is recommended, with or without a supraclavicular incision, and the sternoclavicular joint may or may not be disarticulated ${ }^{1,4,5}$. The incision most often described in relation to cases of extrathoracic aneurysms of the subclavian artery is a supraclavicular access, although there are also reports of combination supraclavicular and infraclavicular incisions or cervicotomy, depending on the peculiarities of each patient $t^{1,3,4}$. For aneurysms of the axillary artery, surgical access can vary from infraclavicular incisions to incisions along the vessel path, above the pulsating mass, and the extent of access depends on the case in question. ${ }^{7}$ In the first case described here, disarticulation of the sternoclavicular joint and displacement of the clavicle downwards in the surgical field allowed sufficient access for surgery via a single supraclavicular incision, in a patient who had already undergone a sternotomy for myocardial revascularization. In the second case, a surgical approach within the topography of the aneurysmal dilatation provided adequate access, with no complications involving the brachial plexus, which was adjacent to the aneurysm.

Interposition of dacron, polytetrafluoroethylene (PTFE) or saphenous vein grafts are also described in the literature on treatment of these patients ${ }^{1,4}$. However, since there is always a fear of infectious complications with synthetic prostheses and since it was possible to draw the arterial stumps together without creating tension, we employed end-to-end anastomosis in both cases, with good long-term results.

There are reports in the literature reports of endovascular treatment of aneurysms in the subclavian-axillary segment, ${ }^{6,9,15,20,21}$ whether as a first 
option or for patients in which the clinical conditions for major conventional surgical procedures are poor. Despite the existence of reports of endovascular treatment in this area, ${ }^{6,9}$ the low incidence rate of true aneurysms in this topography makes it difficult to compare the long-term results of this option in relation to conventional surgery, which remains the standard treatment recommended in the literature. Additionally, the fact that the upper extremity has extensive collateral circulation has been considered a potential source of leakage when endoluminal treatment is chosen ${ }^{9}$. A hybrid treatment has also been described for a complex case involving a patient with Marfan syndrome and an aneurysm of the right subclavian artery, with previous surgery for type A dissection of the aorta ${ }^{10}$.

Both of the patients described here underwent conventional surgery via approaches that provided the access needed to conduct safe procedures with good long term outcomes. In terms of etiologies, in the subclavian aneurysm case the first hypothesis was an infectious aneurysm, in view of the history of infectious endocarditis, but this was not confirmed by pathology findings, which indicated an atherosclerotic aneurysm. The axillary artery aneurysm in a young women was diagnosed as congenital. The majority of aneurysms of the subclavian artery are atherosclerotic (around 60\%), other causes are related to Marfan syndrome or another connective tissue disease in around $10 \%$ of cases ${ }^{1,4,12}$. The histology of aneurysms linked with Marfan syndrome may or may not reveal cystic necrosis of the arterial tunica media ${ }^{18,19}$. In young patients, aneurysms in this topography may be traumatic, infectious, congenital or linked with the thoracic outlet syndrome or with repetitive rotational movements of the shoulder in athletes ${ }^{1,3,4,7,19}$. Aneurysms of the axillary artery are extremely rare in the literature. There is a report of conventional surgical treatment of an axillary aneurysm secondary to thoracic outlet syndrome ${ }^{3}$. There are also reports of two cases of young patients, one 21 and the other 22, with congenital aneurysms of the subclavian artery ${ }^{12}$.

In summary, aneurysms of the subclavian and axillary arteries are rare and when found surgery is indicated in order to prevent complications. The approach should be chosen on a case-by-case basis, depending on the topography of the aneurysm and the patient's characteristics.

\section{REFERENCES}

1. Salo JA, Ala Kulju L, Heikkinen S, Bondestan S, Ketonen P, Luosto R. Diagnosis and Treatment of Subclavian Artery Aneurysms. Eur Vasc Surg. 1990;4:271-4. http://dx.doi.org/10.1016/ S0950-821X(05)80206-3

2. Hobson II RW, Israel MR, Lynch TG. Axilosubclavian arterial aneurysms. In: Bergan JJ, Yao JST. Aneurisms - Diagnosis and Treatment. New York: Grune and Stratton; 1982. p. 435.

3. Thomazinho F, Sardinha WE, Silvestre JMS, Morais D Fo Motta F. Complicações arteriais da síndrome do desfiladeiro torácico. J Vasc Bras. 2008;7(2):150-4. http://dx.doi.org/10.1590/ S1677-54492008000200009

4. Davidović LB, Marković DM, Pejkić SD, Kovacević NS, Colić MM, Dorić PM. Subclavian Artery Aneurysms. Asian J Surg. 2003;26(1):711. http://dx.doi.org/10.1016/S1015-9584(09)60206-2

5. Akar H, Sarac A, Iriz E, Kolbakir F, Dermican S. Intrathoracic Aneurysm of the Right Subclavian Artery. Acta Chir Belg. 2004;104:730-2. PMid:15663285.

6. Sullivan TM, BacharachJM, Perl J, Gray B. Endovascular Management of unusual aneurysms of the axillary and subclavian arteries. J Endovasc Surg. 1996;3:389-95. http:// dx.doi.org/10.1583/1074-6218(1996)003\%3C0389:EMOUAO\% 3E2.0.CO;2

7. Malik MK, Kraev AI, Hsu EK, Clement MHC, Landis GS Spontaneous axillary artery aneurysm: a case report and review of the literature. Vascular. 2012;20:46-8. PMid:22328621. http:// dx.doi.org/10.1258/vasc.2011.cr0293

8. Argotte AF, Giron F, Bilfinger TV. Bilateral subclavian aneurysms with pseudocoarctation of the aorta. Case report and review of the literature. J Cardiovasc Surg. 1998;39:747-50.

9. Troutman DA, Mohan CR, Samhouri FA, Sohn RL. Aneurysms Open Repair and Endovascular Covered Stent Placement in the Management of Bilateral Axillary Artery. Vasc Endovasc Surg. 2010;44:708-9. PMid:20675316. http://dx.doi. org/10.1177/1538574410377239

10. Sacchi AA, Medeiros AZ, Ribeiro R Fo. Tratamento endovascular híbrido de aneurisma da artéria subclávia associado à síndrome de Marfan:relato de caso. J Vasc Bras. 2008;7(2):144-9. http:// dx.doi.org/10.1590/S1677-54492008000200008

11. Clagett GP. Upper Extremity Aneurysms. In: Rutherford RB. Vascular Surgery. 5th ed. W. B. Saunders Company; 2000. p. $1356-1369$.

12. Stahl RD, Lawrence PF, Bhirangi K. Left subclavian artery aneurysm: Two cases of rare congenital etiology. J Vasc Surg. 1999;29:715-8. http://dx.doi.org/10.1016/S0741-5214(99)70319-8

13. Bin HG, Kim MS, Kim SC, Keun JB, Lee JH, Kim SS. Intrathoracic aneurysm of the right subclavian artery presenting with hoarseness: a case report. J Korean Med Sci. 2005;20(4):674-6. PMid:16100464 PMCid:PMC2782168. http://dx.doi.org/10.3346/ jkms.2005.20.4.674

14. Takagi H, Mori $\mathrm{Y}, \mathrm{Umeda} \mathrm{Y}$, et al. Proximal left subclavian artery aneurysm presenting with hemoptysis, hoarseness, and diplopia: repair through partial cardiopulmonary bypass and perfusion of the left common carotid artery. Ann Vasc Surg. 2003;17(4):461-3. PMid:14670028. http://dx.doi.org/10.1007/s10016-003-0014-1

15. Bates MC, Aburahma AF, Crotty B. Successful urgent endovascular surgery for symptomatic subclavian artery aneurysmal compression of the trachea. Catheter Cardiovasc Interv. 2005;64(3):291-5. PMid:15736257. http://dx.doi.org/10.1002/ ccd.20289 
16. Windfuhr JP, Schubert D, Remmert S. Aneurysm of the subclavian artery. An unusual cause of dysphagia. HNO. 2004;52(12):1097-102. PMid:15029424. http://dx.doi.org/10.1007/ s00106-004-1043-y

17. Delap TG, Jones SE, Johnson DR. Aneurysm of an aberrant right subclavian artery presenting as dysphagia lusoria. Ann Otol Rhinol Laryngol. 2000;109(2):231-4. PMid:10685579.

18. Nawa S, Ikeda E, Ichihara S, Sugiyama N, Takagaki K, Kunitomo T. A True Aneurysm of Axillary-subclavian Artery with Cystic Medionecrosis: An Unusual Manifestation of Marfan Syndrome. Ann Vasc Surg. 2003;17:562-64. PMid:14738086. http://dx.doi. org/10.1007/s10016-003-0045-7

19. Morisaki K, Kobayashi M, Miyachi H, et al. Subclavian Artery Aneurysm in Marfan Syndrome. Ann Vasc Surg. 2012;26:731.e1-4.

20. Danzi GB, Sesana M, Bellosta R, Capuano C, Baglini R, Sarcina A. Endovascular treatment of a symptomatic aneurysm of the left subclavian artery. Ital Heart J. 2005;6(1):77-9. PMid:15773278.

21. Corral JS, Zúñiga CG, Sánchez JB, Guaita JO, Basail AM, Gimeno CC. Treatment of aberrant right subclavian artery aneurysm with endovascular exclusion and adjunctive surgical bypass. J Vasc Interv Radiol. 2003;14(6):789-92. PMid:12817048. http://dx.doi. org/10.1097/01.RVI.0000079990.80153.FE

\section{Correspondence \\ Vanessa Prado dos Santos \\ IHAC-UFBA \\ Rua Barão de Jeremoabo (PAF IV), s/n - Ondina \\ CEP 40170-115 - Salvador (BA), Brazil Fone: +55 (71) 3283-6799 \\ E-mail:vansanbr@hotmail.com}

Author's information

FPE is a vascular and endovascular surgeon from the School of Medical Sciences, Santa Casa de São Paulo (FCMSCSP) AVF is an MD from the School of Medical Sciences, Santa Casa de São Paulo (FCMSCSP)

VPS is a PhD in Surgery from the School of Medical Sciences, Santa

Casa de São Paulo (FCMSCSP), and professor at the Professor

Milton Santos Institute for Humanities, Arts, and Sciences (IHAC) Universidade Federal da Bahia (UFBA)

GSN is an MSc in Surgery from the School of Medical Sciences, Santa Casa de São Paulo (FCMSCSP)

ARF is an MSC and a PhD in Surgery from the School of Medical

Sciences, Santa Casa de São Paulo (FCMSCSP) and professor of Vascular and Endovascular Surgery at the School of Medical Sciences, Santa Casa de São Paulo (FCMSCSP).

RAC is a PhD, adjunct professor, and head of the Discipline of Vascular and Endovascular Surgery at the School of Medical Sciences, Santa Casa de São Paulo (FCMSCSP)

Author's contributions Conception and design: FPE, AVF and VPS Analysis and interpretation: FPE, AVF, ARF, VPS Data collection: FPE, AVF Writing the article: FPE, AVF, GSN, VPS Critical revision of the article: FPE, AVF, VPS, GSN, ARF, RAC Final approval of the article*. FPE, AVF, VPS, GSN, ARF, RAC Statistical analysis: N/A

Overall responsibility: FPE, AVF, VPS, GSN, ARF e RAC Obtained funding: None.

*All authors should have read and approved of the final version of the article submitted to I Vasc Bras. 